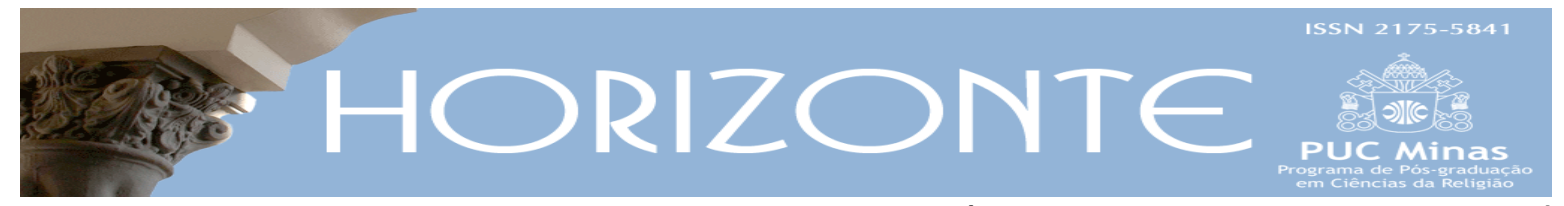

Temática Livre - Artigo original

DOI - 10.5752/P.2175-5841.2015v13n37p446

\title{
A imagem da esposa de Cristo na eclesiologia de Balthasar
}

\author{
The image of the spouse of Christ in the ecclesiology of Balthasar
}

\author{
Pe. Geraldo Luiz Borges Hackmann*
}

\begin{abstract}
Resumo
O artigo analisa a imagem da esposa de Cristo aplicada à Igreja segundo o pensamento do teólogo suíço Hans Urs Von Balthasar. Após a introdução, na qual o leitor vem introduzido brevemente em seu pensamento e trabalho teológico, particularmente na Teodramática, onde se encontra a fonte principal para o estudo em questão, o artigo aborda os três conceitos preliminares, indispensáveis para compreender o seu pensamento eclesiológico: a relação entre o masculino e o feminino, a missão como conceito fundamental e a Igreja como pessoa. Após, o artigo expõe o pensamento deste teólogo sobre a Igreja como esposa de Cristo, apresentando a fundamentação bíblica e patrística, a imagem da esposa de Cristo como articulação da relação entre homem e mulher, a fecundidade na fundação da instituição eclesial e a compreensão de Maria como anima ecclesiastica. Como conclusão, o artigo estuda a possibilidade de uma eclesiologia desenvolvida a partir da compreensão da Igreja como esposa de Cristo.
\end{abstract}

Palavras-chave: igreja; esposa de Cristo; Balthasar.

\begin{abstract}
This article analyses the image of the spouse of Christ applied to the Church according to the thought of the Swiss theologian Hans Urs von Balthasar. After an introduction, where the reader is introduced briefly to his thought and work, particularly the Theodramatic, where one finds the main source for the study in question, the article deals with three previous concepts, indispensible to understand his ecclesiological thought: the relationship between man and woman, the mission as a fundamental concept and the Church as person. Following that, the article shows the thought of this theologian about his understanding of the Church as Christ's spouse, presenting its biblical and patristic rationale, the image of Christ's spouse as the articulation of the relationship between man and woman, fecundity in the foundation of the ecclesial institution and the understanding of Maria as anima eclesiastica. As a conclusion, the article studies the possibility of an ecclesiology being developed from the understanding of the Church as Christ's spouse.
\end{abstract}

Keywords: church; Christ's spouse; Balthasar.

\footnotetext{
Artigo recebido em 05 de junho de 2014 e aprovado em 06 de março de 2015.

* Doutor em Teologia e Professor da Faculdade de Teologia da Pontifícia Universidade Católica do Rio Grande do Sul. País de origem: Brasil. E-mail: gborgesh@pucrs.br.
} 


\section{Introdução}

Uma das primeiras dificuldades para quem desejar estudar Balthasar ${ }^{1}$ é a maneira como ele escreve suas obras: ele aborda os temas teológicos em vários lugares de sua obra. Ele vai expondo seu pensamento pouco a pouco, o que exige a leitura de várias obras para que o leitor possa entender seu pensamento. Ele não escreve como teólogo sistemático, ou como um historiador ou exegeta. Aldo Moda o compara com um grande rio: água abundante, que vai formando meandros na medida em que avança e irrigando diversos terrenos (MODA, 1978, p. 566). Balthasar não tem o objetivo de sistematizar seu pensamento. Ele não foi um teólogo sistemático, como muitos teólogos de renome o foram, pois como afirma Angelo Scola, o estilo teológico de Balthasar não reside na "fundação sistemática de sua teologia", o que impede de "encerrar a obra balthasariana em um sistema" (SCOLA, 1997, p. 17).

Outra dificuldade é a extensão de sua obra. Ele publicou 120 volumes, 532 artigos, 144 contribuições, 110 traduções, 29 antologias, 103 prefácios, 93 recensões. Ainda foi diretor de edição de 13 coleções, totalizando 440 volumes. Também foi cofundador da revista Communio. Entre os anos de 1940 a 1950, ele se ocupa com os ditados espirituais de Adrienne von Speyr. A publicação destes ditados se estende de 1947 a 1990, totalizando 62 volumes. Ele afirma que a sua missão teológica é inseparável da missão espiritual de Adrienne von Speyr ${ }^{2}$. E, quase no final de sua vida, por ocasião da recepção do prêmio Mozart, oferecido pela Fundação Goethe, no dia 22 de maio de 1987, em Insbrück, ele confessa ter escrito demais (BALTHASAR, 1983).

\footnotetext{
${ }^{1}$ Hans Urs von Balthasar nasceu em Lucerna, na Suíça, no dia 12 de junho de 1905, e morreu em Bale, no dia 26 de junho de 1988 . Seu pai chamava-se Oskar Von Balthasar e sua mãe Gabrielle Apor e se casaram no dia 21 de junho de 1904. Seu pai era arquiteto. Ele teve uma irmã, chamada Renée, nascida em 1908, e um irmão, Dieter, nascido em 1913.

${ }^{2}$ A 08 de dezembro de 1944, ele funda, juntamente com Adriana Von Speyr, o Instituto São João, que se tornará um instituto secular com a Provida Mater de Pio XII.
} 
A leitura de sua obra faz o leitor entrar em contato com a literatura, filosofia3, teologia4 e, particularmente, os Santos Padres5, pois a sua obra transita nesses campos com desenvoltura, dando a conhecer o pensamento rico desse teólogo, não só dos mais diversos autores em Teologia, mas também em outros saberes. Assim, é possível verificar a sua envergadura cultural e intelectual. Ele demonstra a capacidade de empreender um trabalho sobre um número incalculável de autores, pensadores, poetas, filósofos, teólogos, dramaturgos e artistas. O Cardeal Daniélou o considerava o homem mais culto do tempo (DANIÉLOU, 1974, p. 93).

O método de seu pensamento é a visão de conjunto, fruto, segundo Mario Saint-Pierre, de sua capacidade de ver o todo em sua parte, ou seja, ver o conjunto em cada parte (SAINT-PIERRE, 2001, p. 44). Fr. Yves Tourenne escreve, no prefácio à reedição da obra $O$ complexo antiromano, que o método de Balthasar, assim como na maior de suas obras, é “integrar”, ou seja, "ver a multiplicidade na unidade originária de toda a Igreja, e ver esta unidade tão rica que funda uma pluralidade” (apud BALTHASAR, 1998, p. 6). Assim é a obra Epílogo (Epilog), com a qual ele concluiu a grande Trilogia em 1987, que permite um olhar de conjunto do cristianismo. A Trilogia, com um total de 7.052 páginas no original, se divide em função de três transcendentais, isto é, três qualidades do ser, que são a beleza, a bondade e a verdade. Com a beleza, ele funda uma estética teológica ao publicar $A$ glória e a cruz (Herrlichkeit), com sete volumes. Com a bondade, ele escreve $A$ dramática divina (Theodramatik), com cinco volumes. E com a verdade, ele publica A Teologia (Theologik), com quatro volumes, incluído o Epílogo (SAINTPIERRE, 2001, p. 43-54).

\footnotetext{
${ }^{3}$ Do ponto de vista filosófico, Balthasar foi influenciado por E. Pryzwara ao assumir dele o conceito de analagio entis como analogia dos transcendentais e, também, a perspectiva meta-antropológica (BALDINI, 2003, p. 36-41; SCOLA, 1997, p. 29-42). Balthasar cita a obra de Erich Przywara: Analogia entis. In Lexikon für Theologie und Kirche. Freiburg: Herder, 1986, col. 468-473.

${ }^{4}$ Do ponto de vista teológico, Balthasar foi influenciado por Barth com o conceito de "universal concreto" aplicado a Jesus Cristo. Uma das obras de Barth que influenciou Balthasar: BARTH, K. Kirchliche Dogmatik, 1. Zürich, 1932 (BALDINI, 2003, p. 41-48). A propósito, ver a seguinte obra: GAUTIER, B. Balthasar em dialogue avec Barth. Paris: Desclée de Brouwer, 2014, 659p.

${ }^{5}$ Balthasar foi introduzido nos estudos patrísticos no período de sua formação teológica em Lião por Henri de Lubac. Além de Santo Agostinho, ele se deixou influenciar por Ireneu, Orígines, Gregório de Nissa e Máximo, o Confessor. Sobre sua formação patrística, ver o capítulo sexto de A. BALDINI, 2003, p.103-121. Ver também o terceiro capítulo da obra de GUERRIERO, 2010, p. 47-70.
} 
A visão eclesiológica de Balthasar encontra-se, sobretudo, na sua obra intitulada Teodramática - Theodramatik ${ }^{6}$, segundo o título do original alemão, ou Teodrammatica, segundo o título dado pela tradução italiana7. Esta obra pode ser considerada a parte central de sua trilogia, que pode ser comparada a um trítico. Trata-se de uma obra em 4 tomos e 5 volumes: Prolegômenos (I), As pessoas do drama: O homem em Deus (II, 1) e As pessoas em Cristo (II, 2), A ação (III) e O ato final (IV). Essa obra foi pensada como um grande drama: há a ambientação (tomo I), a cena (tomo II, volume 1), a apresentação dos atores (tomo II, volume 2), o drama (tomo III) e o ato final (tomo IV). A obra aborda a salvação realizada por Jesus Cristo. O ponto de vista de Balthasar é antropológico: ele contempla a liberdade humana em sua relação com a liberdade divina, o que está no coração do “drama”, porque o drama consiste justamente nesta relação (tomo II, v. 1). Esta questão não pode receber resposta concreta a não ser em Jesus Cristo que, segundo o Concílio de Constantinopla III (680-1), uniu a liberdade divina e a liberdade humana em sua pessoa. Eis porque a reflexão deve se deslocar a um nível mais profundo, o da cristologia (tomo II, v. 2). Cristo só se revela no cumprimento de sua missão recebida do Pai ("a ação"), o quer dizer que a cristologia requer uma interpretação soteriológica (tomo III). O drama se conclui, contudo, na escatologia (tomo IV: o desfecho), e este último ponto de vista, o fundamental para Balthasar, é o da doutrina trinitária.

Além de ser uma obra de grande fôlego, pois são 2.480 páginas no original alemão, que exigem muita atenção do leitor para poder acompanhar o pensamento, com argumentação rica em citações filosóficas, patrísticas e teológicas, um volume está relacionado ao outro. Assim, não basta ler apenas uma parte específica de sua obra, mas é preciso lê-la toda, pois o drama vai se esclarecendo tomo a tomo. As interrogações apresentadas em um volume são respondidas apenas no seguinte. Um tema se aprofunda melhor no seguinte.

\footnotetext{
${ }^{6}$ Einsielden: Johannes Verlag: tomo I, Tomo II: volume 1 (1976), volume 2 (1978); tomo III (1980); Tomo IV (1983).

${ }^{7}$ A obra TeoDRAMMATICA foi publicada em italiano pela editora Jaca Book. O volume II/1 do original alemão corresponde ao volume 2 da tradução italiana, publicado pela primeira vez em 1982; o volume II/2 corresponde ao volume 3, publicado em 1983; o volume III corresponde ao 4, publicado em 1986; o volume IV corresponde ao volume 5, publicado em 1985. Aqui será citada a tradução italiana, em sua última edição.
} 
Além desta obra, sua eclesiologia encontra-se na obra intitulada $O$ complexo antiromano (BALTHASAR, 1974), onde ele reflete sobre o princípio petrino e explica como compreender a dimensão institucional da Igreja, além de analisar, como o título indica, o complexo antiromano que assola a Igreja desde muito tempo. Além dessa obra, sua eclesiologia também se encontra na obra Sponsa Verbi, publicada em 1961 (BALTHASAR, 2001). Há, ainda, outras obras que convergem para o mesmo tema, como Schleifung der Bastionem (1952), Klarstellungen (1971), Kirche als Caritas (1971), Papst heute (1971), Warum ich in der Kirche bleibe? (1971), Spiritus Creator (1972), Pneuma und Institution (1974), Die Kirche lieben (1974), Christlicher Stand (1977) e Neue Klarstellungen (1979).

Pois é neste contexto que ele expõe sua concepção sobre a Igreja. Todavia, no presente artigo se fez a opção de não apresentar uma visão completa sobre a concepção eclesiológica de Balthasar, o que seria impossível, devido à complexidade de seu pensamento e ao que foi exposto acima, mas se decidiu estudar apenas um aspecto, que parece fundamental para compreender a originalidade de Balthasar: a Igreja como esposa de Cristo. Assim, o intuito é muito mais expor a alma de Balthasar, quando ele escreve sobre a Igreja, do que tentar reproduzir toda a riqueza da elaboração de seu pensamento eclesiológico, que, aliás, está entranhado em todo o conjunto de sua vasta obra.

\section{Conceitos prévios}

Inicialmente, serão abordados três conceitos prévios necessários para compreender o pensamento de Balthasar sobre a Igreja como esposa de Cristo, pois são pressupostos a partir dos quais ele elabora seu pensamento eclesiológico e mariológico. No entanto, serão apresentadas apenas algumas características de seu pensamento, sem o objetivo de aprofundar exaustivamente cada um dos pontos a seguir expostos. O ponto de partida é antropológico, com o primeiro conceito, o segundo é cristológico e o terceiro e último é eclesiológico e mariológico. 


\section{a) A relação entre o masculino e o feminino}

Ao analisar o homem no plano natural (BALTHASAR, 2012, v.2 p. 317-402), Balthasar aborda a relação entre o masculino e o feminino (BALTHASAR, 2012, v. 2, p. 344-360). Ele parte da análise dos dois relatos da criação no livro do Gênesis: o primeiro, no capítulo 1, e o segundo, no capítulo 2. Após o "muito bom" da primeira narração, ele cita o "não é bom que o homem esteja só" do segundo relato ( $G n$ 2,18). Por isso, Deus lhe deu um complemento humano (cf. Gn 2,18.23) como ajuda e como imagem (BALTHASAR, 2012, v. 2, p. 344).

Entre a mulher, criada da costela de Adão, e os animais, a quem Adão dá nome, após desfilarem diante dele, como sinal de domínio, há uma diferença essencial: ela é sua parceira (Gegenbild, em alemão). Com isto, ele a reconhece como "osso dos meus ossos e carne da minha carne" ( $G n$ 2,23), e, desse modo, escapa eternamente de sua dominação. Como parceira, ele reconhece nela a mesma natureza humana, embora com uma diferença, fruto da sexualidade diferente da sua: Adão é masculino e Eva feminina. Todavia, homem e mulher têm em comum a mesma natureza humana, mas na diferença sexual, tornando a pessoa, desde a criação, uma unidade dual. Esta diferença sexual os faz compreender a si mesmos de modo diferente e perceber a própria existência também de modo diverso. No entanto, não significa que a unidade formada pelo homem e pela mulher possa ser multiplicada por dois, pois o homem e a mulher formam uma polaridade, onde cada polo é irredutível ao outro, mas cada polo se refere necessariamente ao outro.

Adão não encontra uma companheira entre os animais, mas sim em Eva. Isto significa que, além dele reconhecer que Eva é da mesma natureza que a dele, a sua busca não é meramente cósmica, isto é, limitada às dimensões do mundo sensível, mas espiritual, no sentido de que Adão, por seu espírito, transcende a totalidade do mundo sensível, o quer dizer que o companheirismo entre os dois comporta em que Adão se dá conta que não se realiza em si mesmo, mas encontra a sua realização plena na abertura para Eva. O mesmo vale para Eva em relação a 
Adão. É que o eu do ser humano está sempre à procura do tu. É a alteridade própria do ser humano, que o levará a encontrar-se com o outro, mas sem jamais apropriar-se dele. A atitude de alteridade é própria da liberdade do ser humano, que se abre exclusivamente à liberdade absoluta e divina, e que se inscreve na constituição corporal, ao mesmo tempo, complementar e diferente dos dois sexos.

Balthasar, assim, aborda a questão do corpo e do espírito. Ele afirma que não se pode restringir a reflexão sobre o homem ao aspecto cósmico, mas é necessário ir além, ao meta-cósmico, pois a busca do homem pelo outro é uma questão espiritual. É um movimento ascendente do corpo para o espírito, presente no primeiro relato da criação, e, ao mesmo tempo, descendente do espírito para o corpo, expresso pelo segundo relato da criação. Assim, Adão encontra Eva em um nível espiritual, pois quer alguém que lhe esteja vis-à-vis e lhe corresponda: o carnal de forma espiritual e o espiritual de forma carnal (BALTHASAR, 2012, v. 2, p. 344). Desse modo, ninguém é homem integralmente, pois sempre precisa do tu para se realizar como eu humano. Segundo E. Pryzwara, citado por Balthasar, é a "reciprocidade dialética" (BALTHASAR, 2012, v. 2, p. 359, nota 76).

Outro elemento da reflexão de Balthasar é a dimensão de fecundidade própria do masculino e do feminino, onde ele cita K. Barth, para quem no tema da fecundidade se encontra uma antecipação plenária de Cristo e da Igreja (BALTHASAR, 2012, v. 2, p. 359, nota 113). Balthasar pensa que, seguindo Gregório de Nissa, no carnal há um eco atenuado da ideia mais alta do humanismo integral (BALTHASAR, 2012, v. 2, p. 360). Ou seja, a relação sexual entre homem e mulher, por si só, não é capaz de esgotar a necessidade de complementaridade e levar o homem e a mulher à plenitude humana. Com esse modo de pensar, Balthasar está abrindo uma janela para que se compreenda a fecundidade em um nível espiritual e se possa falar da fecundidade de Cristo e da Igreja, além da fecundidade de Maria. 


\section{b) A missão como conceito fundamental}

Antonio Baldini, em seu estudo sobre a obra $O$ complexo antiromano, em que analisa o princípio mariano e o princípio petrino, observa que a missão dos personagens citados - a constelação cristológica (BALTHASAR, 1998, p. 162-172; BALDINI, p. 60-64) - nem sempre aparece adequadamente aprofundada (BALDINI, p. 228). É que Balthasar aborda o tema da missão em diversos lugares de sua obra, de modo particular, na obra Teodramática, onde ele aprofunda o conceito de missão. Esta obra é posterior à obra estudada por A. Baldini. Por isso, é possível afirmar que a missão aparece como um conceito básico na obra de Balthasar. É o seu "guia hermenêutico", conforme a sua própria expressão (BALTHASAR, 2012, v. 3, p. 141), imprescindível para se poder compreender a sua eclesiologia e sua mariologia.

A missão é um conceito fundamental para Balthasar, porque o homem não pode saber quem ele é, na sua unicidade qualitativa, a não ser a partir de Deus e da missão que Deus lhe confia. Por isso, Balthasar afirma que a pessoa descobre seu ser pessoal a partir de sua missão, porque ele a entende sempre do ponto de vista teológico e não natural. E ele entende o termo pessoa como "pessoa teológica" ${ }^{\text {, }}$ que é um sujeito que acolheu a sua missão, e que, a partir dela, se descobre e se entende como pessoa. É na missão de Cristo que alguém recebe a sua missão e é na pessoa de Cristo que alguém se torna pessoa. Neste sentido, a pessoa de Cristo e sua missão são entendidas como arquétipo para todos os demais seres humanos. Ele é a "pessoa arquétipa" 9 para todas as demais pessoas (BALTHASAR, 2012, v. 3, p. 189).

Em Cristo, há a coincidência entre seu ser como pessoa e a seu papel no mundo enquanto missão. A sua pessoa e a sua missão coincidem (BALTHASAR,

\footnotetext{
${ }^{8}$ A expressão "pessoa teológica” encontra-se em BALTHASAR, 2012, v. 3, p. 196-206. Quando a pessoa se identifica com a sua missão, a partir de Jesus Cristo, ela se torna uma "pessoa teológica".

9 Balthasar usa a palavra "arquétipo" em sentido filosófico, enquanto entende a vida real como um processo teatral, onde Cristo é o modelo para todas as pessoas. Ele é o ator "modelo" a partir do qual todos os demais atores recebem sua identidade pessoal (cf. BALTHASAR, 2012, v. 3, p. 189).
} 
2012, v. 3, p. 142). É que a sua missão é a forma econômica de sua processão eterna em Deus ${ }^{10}$. Ele vive sua consciência humana perfeitamente como missão (BALTHASAR, 2012, v. 3, p. 195). Isto implica em que Jesus tem consciência de sua missão e a concretiza de forma livre (BALTHASAR, 2012, v. 3, p. 156-163; 180189), pois se sabe enviado pelo Pai para realizar a obra da salvação da humanidade pela morte na cruz e pela ressurreição (cf. $M t$ 20,28; $L c$ 3,22). Cada vez que Jesus repete que é enviado, como em $L c$ 4,33 e $M c$ 1,38, está expressando sua consciência messiânica de trazer para o mundo, por meio de sua pessoa, um acontecimento salvífico definitivo: chamar os pecadores à conversão e à penitência (cf. $M t$ 20,28 e Mc 9,13) (BALTHASAR, 2012, v. 3, p. 144). A sua missão, desse modo, é universal (BALTHASAR, 2012, v. 3, p. 216).

Ao ratificar livremente em seu eu pessoal a missão recebida do Pai e de encarná-la totalmente no mundo, ele se une ao Pai e mostra, por meio da diferença entre decidir e obedecer, uma mediação harmoniosa entre o Pai e o Filho, só possível por meio do Espírito Santo. Assim fica clara a relação entre Cristo e o Espírito Santo na encarnação do Verbo, de acordo com Lc 1,35. É dessa maneira que Balthasar entende a presença da Trindade na missão do Filho (BALTHASAR, 2012, v. 3, p. 172-180).

É em Jesus Cristo, o único homem verdadeiro, modelo e origem de toda a humanidade e pessoa arquétipa, que cada pessoa é eleita e recebe a sua missão própria. Na medida em que o eleito acolhe efetivamente essa missão, ele é introduzido neste espaço aberto por Cristo, onde pessoa e missão coincidem. É assim que ele se torna "pessoa teológica" em Jesus Cristo, ou seja, realiza-se como pessoa ao participar da missão universal de Cristo. E, hoje, esta missão se realiza permanentemente na Igreja até o fim dos tempos, pois ela é sacramento universal de salvação para toda a humanidade (Cf. Lumen Gentium, n. 1). E cada batizado, ao se abrir ao dom de Cristo, participa de sua missão universal (BALTHASAR, 2001, p. 175).

\footnotetext{
${ }^{10}$ Aqui Balthasar explica como entende a relação entre a trindade imanente e a trindade econômica: TeoDRAMMATICA, v. 3, p. 148466-469; TeoDRAMMATICA, v. 4, p. 295-305. A missão do Filho como forma da sua processão eterna: TeoDRAMMATICA, v. 3, p. 156163.
} 


\section{c) A Igreja como pessoa}

Assim como alguém se torna pessoa ao receber a sua missão, e como todas as missões se entrecruzam, a comunidade de discípulos se funda na abertura recíproca das pessoas, que se tornam um ser pessoal. E também Maria. A sua missão é universal (por razões cristológicas), e "assim católica, assim inteiramente eclesial” (BALTHASAR, 2012, v. 3, p. 283). O paralelo entre Cristo e Maria está presente na exegese do Cântico dos Cânticos como Igreja-esposa, polarizada na pessoa de Maria, e isto, por sua vez, cristalizada em torno do corpo dos fiéis (BALTHASAR, 2001, p. 157).

Na obra Sponsa Verbi, mais tarde também na obra Quem é a Igreja, Balthasar explica que a Igreja não é o quê, tampouco se pergunta "que coisa é a Igreja", mas ele sublinha que a pergunta adequada é "quem é a Igreja". Tal forma de abordar a Igreja tem como pressuposto que a Igreja é alguém, não uma coisa, mas uma pessoa, um sujeito integral (BALTHASAR, 2000, p. 29-31). A razão de Balthasar considerar a Igreja uma pessoa está na Teodramática, onde ele afirma que a missão de Cristo requer um vis-à-vis pessoal em Maria-Igreja. A verdade da encarnação requer, de fato, que Jesus, sendo masculino, se refira a um ser feminino e dependa deste para sua fecundidade, como todos as pessoas. Enquanto Jesus é um homem individual, limitado pelo tempo e pelo espaço, tem como vis-à-vis um ser feminino individual, concreto, também com seu limite de espaço e de tempo. Enquanto Jesus é uma pessoa divina, com a sua missão, que se estende a todo o mundo e a todos os tempos, ele tem como vis-à-vis um ser feminino de dimensão universal, que é a Igreja. Segundo a declaração do Concílio de Calcedônia (451), os dois aspectos - humano e divino - estão sempre unidos "sem confusão, sem mudança, sem divisão, sem separação" ( $D H$ 302). Portanto, Maria e a Igreja permanecem inseparáveis, mesmo sendo distintas. Esta é a explicação pela qual a Igreja é fundamentalmente pessoa. 
A consideração da Igreja como pessoa não é nova na teologia católica. Y. Congar escreve um artigo, em 1971 (CONGAR, 1971, p. 613-640), onde analisa o desenvolvimento da noção de personalidade da Igreja na tradição teológica da época patrística, quando cita Agostinho e Gregório, à Idade Média. Detém-se em Santo Tomás de Aquino, analisando dez textos, onde mostra a Igreja como personna mystica. Finalmente, Congar aponta alguns autores atuais nos quais se encontra a referência ao Corpo místico e à personalidade da Igreja, tais como P. Cathala, J. Maritain, P. Humbert Clérissat, Dom Anschaire Vonier, P. E. Mura, Charles Journet e, por último, Balthasar.

Balthasar ressoa, de São Paulo, as duas noções: a de corpo de Cristo e a de esposa de Cristo. Enquanto que a Igreja é corpo de Cristo, ela "é simplesmente Cristo”. Ela é a sua extensão e plenitude. Por outro lado, enquanto ela é esposa, a Igreja "não é simplesmente Cristo", pois ela é sua parceira, um vis-à-vis (BALTHASAR, 2001, p. 147 e 192; 2012, v. 3, p. 317 e 318). Ela é a "serva do Senhor" (cf. Lc 1,38). Se a Igreja for separada de Cristo, ela se tornará mera instituição humana. Se a Igreja for simplesmente assimilada por Cristo, ela será divinizada. Ambas as posições estão erradas. Assim, a Igreja não é "puramente humana” nem "puramente divina”.

\section{A Igreja como esposa de Cristo}

Balthasar faz a passagem da imagem da Igreja como corpo de Cristo para a da esposa partindo dos três testemunhos (espírito, água e sangue) do irrepetível amor humano-divino, citados em $1 J o$ 5,6-8, que se relacionam com a essência da Igreja. Esta se encontra na cruz, como a origem da Igreja, que representa, teologicamente, o contributo criador e o resultado da paixão vicária de Cristo pela humanidade. A partir desta afirmação, comum na tradição teológica, ele se pergunta se tal afirmação comporta apenas a compreensão de que só a realidade espírito-corporal do homem-Deus, que se efunde para fora de si em formas sacramentais - e, por conseguinte, a graça trinitária dada à humanidade em figura 
cristológica -, está presente na cruz ou se deva pensar que no crucificado, que morre representativamente, está presente algum elemento da humanidade pecadora que desemboca, de certa forma como uma segunda realidade, na efusão e criação da Igreja. Se for possível aceitar essa última afirmação, segundo ele, o passo para a compreensão da Igreja como esposa de Cristo já está efetuado de maneira imperceptível (BALTHASAR, 2001, p. 156).

\section{a) A fundamentação bíblica e patrística}

Não se trata aqui de expor toda a argumentação bíblica e patrística que Balthasar apresenta para fundamentar a imagem da Igreja como esposa de Cristo, mas apenas citar alguns elementos. Do Antigo Testamento, destaca-se, em primeiro lugar, a relação entre Deus e o povo de Israel, que foi entendida como aliança nupcial. Sião é a noiva prometida em casamento ou, também, a esposa, como se vê, por exemplo, em Is 54,5-6 e $J r$ 2,2. Dentro desta imagem, encontramse os textos que recriminam a atitude de Israel, porque entendida como adultério. Também no Novo Testamento, embora com outras palavras, o mesmo tema está presente, como em $M t$ 21,31-32 (os dois filhos), Lc 7,36-50 (a pecadora perdoada) e Jo 8 (a mulher adúltera). A descrição do amor sensível entre os amantes no livro do Cântico dos Cânticos serve para desenvolver a relação neotestamentária entre Cristo e a Igreja. Assim, o Povo de Deus, tanto da antiga aliança quanto da nova aliança, constitui uma Casta meretrix.

O Novo Testamento emprega muito pouco a imagem das núpcias. As parábolas de Mateus fazem pouca referência direta às núpcias. Em João, apenas na frase do Batista, em 3,29, encontra-se uma referência ao esposo e à esposa, mas proferida em um contexto messiânico, assim como os demais textos onde são citadas as bodas (cf. Jo 1,14; 2,1-11; 2,21; 3,4; 6,33s; 7,37-38; 12,15; 15,1-8; 19,27; 19,34; 20,22; 20,27 e 21,19). Mesmo no Apocalipse não há uma referência clara ao caráter pessoal da Igreja- esposa, a não ser no final do livro, no texto em que o 
Espírito e a Esposa dizem "vem" (cf. Apoc 22,17). Há, porém, dois textos do Novo Testamento que, a partir da encarnação do Verbo (cf. Jo 1,14), referem-se ao corpo e à união sexual em si mesma (BALTHASAR, 2001, p. 153-158). É o caso dos textos de 1 Cor 6,15-17 e Ef 5,31-32.

Porém, Balthasar dá maior atenção à imagem das núpcias existente em Efésios 5,21-32, com a qual ele aprofunda a sua fundamentação bíblica, destacando os seguintes aspectos deste texto bíblico aplicado à Igreja como esposa de Cristo: a comparação entre homem e mulher, de um lado, e de Cristo e a Igreja, de outro, obriga a conceber a imagem da cabeça e do corpo em sentido esponsal e pessoal, enquanto a "cabeça" significa o Senhor do matrimônio, o Esposo, e o "corpo" significa o complemento e a fusão físico-sacramental do matrimônio (BALTHASAR, 2001, p. 150-151).

Tal compreensão exige a manutenção simultânea das duas afirmações: a pessoal e a somática. A pessoal mostra a Igreja como uma "mulher", a quem Cristo amou e por ela se doou, ou seja, é "alguém” já existente, a quem o Senhor amou e se entregou até a morte (cf. $E f$ 5, 24-27), pois purificou-a no banho da água na palavra. A somática diz que a Igreja, tal como é, ou seja, gloriosa, sem mancha e sem ruga, nasce e procede totalmente do acontecimento da cruz. São Paulo foi capaz de manter este paradoxo - "para não dizer contradição", de acordo com Balthasar - unicamente porque recorreu a sua intelecção teológica prévia da doutrina dos sexos, isto é, o nascimento da primeira mulher da costela do primeiro varão, compreendendo-a como carne e sangue do varão e, como tal, pessoa, pela qual ele abandonará pai e mãe e se unirá a sua mulher (v. 31). Neste versículo, Paulo está se referindo ao livro do Gênesis (cf. Gn 2,24), e, assim, pode aplicar a Adão e à Eva. Adão não teve pais para abandonar, por isso o verbo da frase está no futuro, indicando que a realização simultânea dos dois aspectos se dá na relação entre Cristo e a Igreja. Além disso, está presente neste versículo a elevação da relação entre os sexos de tipo ${ }^{11}$ (a imagem da relação homem-mulher) para antítipo

\footnotetext{
${ }^{11}$ Balthasar emprega a palavra "tipo" no sentido grego (typos), para indicar na maternidade de Maria a figura do que há de vir: a maternidade da Igreja. A "virgem Maria gerou primariamente (carnalmente) a cabeça da Igreja e nisto é o typos da Igreja virginal, que,
} 
(fundada na relação entre Deus e os homens), apresentando aquele como um grande mistério em relação a este (BALTHASAR, 2001, p. 151).

Após a reflexão sobre o texto bíblico, Balthasar analisa os Padres da Igreja que comentam o citado texto de Efésios, como também o texto de Filipenses 2. A partir dessa análise, ele conclui que os Padres que falam, de acordo com Paulo, de uma descida e de um afastamento de Cristo do Pai para unir-se à sua esposa, caída na terra e distanciada de Deus, tornam, pela primeira vez, compreensível a expressão paulina segundo a qual Cristo amou a sua Igreja e se entregou por ela na cruz. Ainda mais, que a segunda afirmação introduzida por eles, isto é, que a Igreja é sem mancha e sem ruga, pois foi purificada e glorificada na cruz, precisava desta purificação e dessa glória porque só na cruz e na nova aliança a Igreja chegou a participar destas propriedades. Enfim, Balthasar conclui que estas duas reflexões dos Padres não ultrapassam a lógica do pensamento paulino (BALTHASAR, 2001, p. 151).

E Balthasar, após esta reflexão, se faz três perguntas, a partir da unificação dos dois aspectos que Paulo destaca das duas imagens bíblicas citadas anteriormente, pois são, à primeira vista, inconciliáveis. A primeira pergunta é sobre a Igreja que nasce da morte de Cristo e que preexiste. A segunda é se, em consequência disto, é possível conciliar a Igreja enquanto prolongamento e efusão de Cristo, Deus e homem (será a Igreja como "corpo de Cristo"), e a Igreja que se põe diante dele como "alguém", uma pessoa (será a Igreja como "pessoa" ou "Esposa”). A terceira pergunta é se Paulo poderia ter feito a unificação insinuada, porém não exigida, pelo livro de Gênesis sem o transfundo do pensamento mítico e gnóstico de sua época. E Balthasar responde afirmando que não é necessário pensar que o uso mítico-gnóstico tenha se introduzido nos teologúmenos, pois não fariam parte dos motivos teológicos aí presentes, mesmo se o mítico e o gnóstico estivessem no transfundo da ideia paulina. A prova que ele apresenta é o sucesso da 
imagem da Igreja como esposa de Cristo na época patrística e na exegese da Idade Média, mesmo que baseada nos Padres, que se distancia do pensamento míticognóstico e está aliada à convergência de diversos motivos dentro da Escritura. Entretanto, a imagem da Igreja como esposa de Cristo perdeu a sua força, o que perdura na consciência eclesial até os dias de hoje, dando lugar à imagem de Corpo de Cristo (BALTHASAR, 2001, p. 151-153).

\section{b) A Igreja, esposa de Cristo, como articulação da relação entre o masculino e o feminino}

Balthasar aplica a relação entre o masculino e o feminino para a Igreja a partir da imagem das núpcias, já refletida anteriormente. Se for verdade que o Filho de Deus se fez carne, então ele também assumiu a condição sexuada humana, o que o torna dependente, por causa da fecundidade, de uma pessoa do sexo oposto. Todavia, ele não assume tal condição humana por um ato carnal: o fruto que ele traz, com a ajuda de sua "esposa", é a salvação do mundo. Portanto, o Verbo assume a condição humana sexual a serviço de uma fecundidade espiritual.

Sendo Cristo um ser humano (ele é homem), ele tem uma figura concreta e limitada. Por isso, ele necessita de um vis-à-vis também concreto e limitado, que é Maria. Enquanto Cristo é Deus e a sua missão se estende a todos os tempos e a todos os povos, seu vis-à-vis é a Igreja, que também recebe uma missão para todos os tempos e para todos os povos. Conforme o dogma do Concílio de Calcedônia, Maria e a Igreja não podem ser nem confundidas nem separadas. Nota-se que Balthasar realiza esta passagem para a Igreja através da analogia entre Adão e Cristo e Eva e Maria. Ele entende que Maria precede a Igreja por meio de sua união nupcial com Cristo e, assim, nasce a Igreja. Maria se encontra no núcleo da Igreja através de seu sim, que foi representativo de toda a humanidade.

O ponto de partida para Balthasar é Adão e Eva, enquanto personificam o masculino e o feminino. Aqui se apresentam dois aspectos essenciais. O primeiro 
aspecto é a união na diferença entre o masculino e o feminino, que consiste na comunhão. A diferença irredutível entre os sexos torna possível a união mais íntima, isto é, a união corporal e espiritual. Adão e Eva estão um diante do outro, como pessoas. Como a mulher foi tirada do homem (cf. Gn 2,23), ela é essencialmente resposta (Ant-wort, em alemão), que para Balthasar adquire um sentido de vis-à-vis, compreendido como antítese, e, ao mesmo tempo como para, compreendido como "na direção de", por isso, deve ser entendida como a direção para alguma coisa e a oposição a qualquer coisa. Além disso, a palavra alemã indica também o fim, o objetivo (BALTHASAR, 2012, v. 3, p. 264). Assim, o masculino e o feminino, ao mesmo tempo, se antepõem e estão um para o outro, enquanto são duas pessoas diferentes, mas que se realizam como pessoas no encontro recíproco. E a relação entre Adão e Eva, por sua vez, se torna a imagem análoga que opõe as Pessoas divinas e a sua circumincessão (circumincessio) ${ }^{12}$, ou seja, a presença total de cada um no outro.

O segundo aspecto é a fecundidade. Balthasar entende que a mulher não é apenas um receptáculo passivo do homem, mas a sua acolhida do homem implica em uma atitude ativa, que é o dom da fecundidade. Ela não é apenas um vaso fecundado pelo homem, mas ela está dotada de uma fecundidade própria, que não é uma fecundidade primária, mas uma fecundidade que responde, enquanto formada por ter recebido a fecundidade do homem. Assim, ela pode chegar à sua plenitude e pode tornar-se “a glória do homem” (cf. 1Cor 11,7). E, desse modo, conclui Balthasar, se pode falar de uma missão natural da mulher de modo muito mais apropriado do que de uma missão correspondente ao homem (BALTHASAR, 2012, vol. 3, p. 266). Balthasar ainda observa que a missão de "ser fecundos" e de "submeter todas as coisas" (cf. Gn 1,28) foi dada aos dois. Neste sentido, pode-se designar a missão da mulher em relação à de Adão como a continuação e a consequência de sua processio de Adão. Daí se deduz a verdade que os dois,

\footnotetext{
${ }^{12}$ Circumincessio (do latim circum + incessio) significa estar ao redor. É a palavra técnica para descrever a presença das três pessoas trinitárias umas nas outras, a contínua e interna interrrelação entre as pessoas divinas. Vem do grego pericorese. Balthasar aplica de forma análoga para a relação entre homem e mulher: um se relaciona com o outro, mantendo o que cada um é e em contínua presença no outro.
} 
homem e mulher, não estão somente em comunhão, mas que cada um, por si mesmo, é a imagem de Deus, garantindo, assim, a relação imediata de cada um com Deus (BALTHASAR, 2012, v. 3, p. 264-266).

Há ainda outro aspecto que Balthasar acrescenta a essa reflexão: na medida em que esta é a missão da mulher, isto é, a de receber a fecundidade do homem em sua própria fecundidade e, assim, unir a fecundidade dos dois, ela é, no nível da criação, o princípio propriamente dito da frutificação. Tal afirmação deve ser compreendida no sentido de que o feminino não apenas restitui ao masculino o que dele recebeu, mas que acrescenta algo novo, que integra, sem dúvida, o que recebeu do homem, mas que vai ao encontro dele sob uma forma nova e inesperada. Assim, a mulher dá ao homem uma dupla resposta: uma resposta pessoal e uma resposta que ultrapassa a relação eu-tu e que se caracteriza por ser genérica. Ela é uma resposta na qualidade de reprodução. Aqui, Balthasar quer deixar vaga a questão de como entender a reprodução, sem entrar em discussões mais complexas (BALTHASAR, 2012, v. 3, p. 266-267).

Após a reflexão sobre Adão e Eva, Balthasar dá mais um passo. Agora ele estabelece uma relação análoga entre Deus e a criatura. Ele afirma que a criatura diante de Deus só pode ser secundária, correspondente, "feminina". Porém, é impossível identificar o Criador com Adão, visto que Deus não precisa da criatura como complemento e plenitude. Deus Pai "não tem necessidade de se libertar de sua própria fecundidade", pois engendra o Filho em virtude de seu amor "desinteressado" e não para ter alguém como receptáculo de sua riqueza, e, também, por não estar constrangido a se comunicar para fora de si mesmo, além da resposta dada pelo Filho, que lhe vem não como uma ajuda mas como uma resposta totalmente perfeita. E o Espírito Santo se apresenta como fruto do seu amor. Desse modo, a vida trinitária se revela como um "movimento circular" e eterno, acabada nela mesma e que não precisa do mundo. $\mathrm{E}$ a criação permanece um dom desinteressado do amor bem-aventurado da vida trinitária para com as criaturas indigentes, mantendo a diversidade da relação entre Deus e a criatura e a relação entre o homem e a mulher (BALTHASAR, 2012, v. 3, p. 267-268). 
O passo seguinte é a posição cristológica da mulher. Isto é possível, pois o aspecto terrestre, homem e Deus, e o aspecto supraterrestre, Deus e o mundo, se unem no homem-Deus Jesus Cristo.

Pode-se perceber no homem-Deus Jesus Cristo dois aspectos de sua relação para com a Esposa: um individual, enquanto ele é um homem individual e se relaciona com uma mulher, a sua mãe; o segundo é a relação social enquanto ele exerce a missão recebida do Pai como representante de toda a humanidade (cf. 2Cor 5,19), ou seja, a salvação de todos os seres humanos por meio da morte de cruz e gloriosa ressurreição. Estas duas relações correspondem as duas naturezas de Cristo, a humana e a divina, inseparáveis entre si ( $\mathrm{DH}$ 302). Contudo, é preciso distinguir entre a encarnação em geral e encarnação em uma carne de pecado (cf. $R m$ 8,3) (BALTHASAR, 2012, v. 3, p. 268).

A encarnação em geral, enquanto ele é Deus, pode ser considerada completa sem um complemento feminino, pois o Verbo é a plenitude e se completa em si mesmo (cf. $\mathrm{Cl}$ 1,19 e 2,9). A encarnação em uma carne de pecado aponta para Cristo como segundo Adão, como homem, vir, mesmo ele sendo uma Pessoa divina. Ele é masculino, o novo Adão. E, como tal, como o velho Adão estava vis-à-vis com Eva, do lado aberto de Cristo na cruz se encontra a resposta da mulher. Assim, o mistério do homem e da mulher na primeira criação se torna presente na encarnação, que recebe a sua riqueza misteriosa somente no mysterium de Cristo e da Igreja (cf. Gn 2,24 e $E f$ 5,27.33), sendo possível estabelecer uma analogia entre ambos os mistérios (BALTHASAR, 2012, v. 3, p. 269).

Cristo entrou na série de gerações da humanidade por meio da mulher (cf. 1 Cor 11 e 12). Como esta mulher é mãe de uma criança humana que é pessoalmente Deus, ela deve ser chamada de mãe de Deus, Theotókos ${ }^{13}$. Assim, ela se encontra como mulher em relação a seu filho, que é homem. Para Balthasar, aí está presente a relação entre o masculino e o feminino. Ainda mais: nela também se encontra a

${ }^{13}$ É a definição do Concílio de Éfeso, de 431 (DH 251). 
mulher individual e a mulher social. Como mãe e esposa, diante de Cristo, Maria é uma mulher individual; enquanto recebeu uma missão, a da maternidade divina, ela é a mulher social e representa a Igreja (BALTHASAR, 2012, v. 3, p. 269).

Como mulher individual e social simultaneamente e, ao mesmo tempo, mãe de Deus e esposa, como todas as mulheres, entrelaçando-se estas duas condições: a de mulher individual e social, a de esposa e mãe. Desse modo, Balthasar vê, seguindo M. J. Scheeben ${ }^{14}$, na maternidade de Maria uma "maternidade divina esponsal" ou a "esponsalidade de sua maternidade divina" (BALTHASAR, 2012, v. 3, p. 273, nota 2). Balthasar constata que, habitualmente, a teologia parte da maternidade divina de Maria, o que lhe parece compreensível, pois é onde a sua missão teve início histórico. Todavia, ele se pergunta se esse modo de proceder não obscurece o papel representativo de Maria. Sendo assim, Balthasar afirma não ser suficiente destacar seu papel ao lado da Igreja, como seu arquétipo, seu membro mais ilustre, um membro que coopera com a redenção da humanidade; mas é preciso estabelecer uma mariologia concreta, que destaque não apenas episódios da vida de Maria mas também desenvolva a historicidade concreta de uma mulher que realizou a sua missão por meio da cooperação com Deus, por meio de uma resposta obediente e, ao mesmo tempo, ativa, enquanto gerou e deu ao mundo o filho de Deus. A sua obediência na fé se opõe à desobediência de Eva (BALTHASAR, 2012, v. 3, p. 273-275). Assim, Maria se torna ao mesmo tempo tipo, enquanto mulher arquétipa, de acordo com a tradição patrística, e símbolo real da Igreja (BALTHASAR, 2012, v. 3, p. 273-275; 279-280).

É assim que Balthasar vê a passagem de uma mariologia eclesiotípica, própria da idade patrística, que entende Maria como tipo da Igreja de Cristo, para uma mariologia mais cristotípica, desenvolvida na Idade Média, que, contudo, traz o perigo de introduzir um papel paritário entre Cristo e a Igreja. Por isso, ele entende necessário completar tal visão com várias afirmações bíblicas e teológicas, entre as quais a imagem da esposa do Senhor (BALTHASAR, 2012, v. 3, p. 274275).

\footnotetext{
${ }^{14}$ Balthasar cita a seguinte obra de Scheeben: Dogmatik III (Freiburg 1882), n. 1590 (BALTHASAR, 2012, v. 3, p. 273, nota 2).
} 
Balthasar cita o pensamento da representatividade da humanidade no sim de Maria em Ambrósio de Autpert ( $†$ 784) e em São Bernardo. Reforça tal interpretação a afirmação de Tomás de Aquino, que considera o sim de Maria representativo para toda a humanidade ${ }^{15}$. E acrescenta a opinião de Autpert, que considera que este sim não pode ser pronunciado por nenhuma pessoa individual a não ser por Maria, pois o seu sim é ilimitado. É a idade pós-agostiniana, quando, segundo Balthasar, a Igreja real não é mais capaz de encontrar coragem para identificar-se com a "esposa imaculada sem ruga e sem mancha” ( $E f 5,27)$, como também com os comentários ao Cântico dos Cânticos, que, em determinada época, consideravam a bela sunamita como a Igreja, e começam a interpretar como relativa a sua pureza e como representante só dos membros melhores (BALTHASAR, 2012, v. 3, p. 286). Assim, está ultrapassada a ideia de que a relação entre Maria e a Igreja deva ser compreendida como "gênero e espécie", como entenderam Ambrósio de Autpert e Pascásio Radberto. Este último já entende a maternidade de Maria ligada a sua qualidade de esposa ${ }^{16}$. Para Balthasar, o sim de Maria é solidário com toda a humanidade, porque ela, como Imaculada, isto é, concebida sem pecado, goza de uma infinita capacidade de doação e de amor, além de ter pronunciado seu sim não para si, mas para todos aqueles que têm necessidade da salvação de Israel (BALTHASAR, 1999, v. 4, p. 331).

Portanto, Jesus Cristo é o esposo e a Igreja é a esposa. São duas pessoas concretas e históricas. Ele se fez homem - masculino - e tem um partner concreto, o feminino. Ao mesmo tempo em que ele é homem, tem como partner uma mulher. E esta é Maria. Ao mesmo tempo em que Jesus Cristo é Deus e a sua missão é universal, ele é homem e se relaciona com outra figura histórica, Maria, que em virtude de sua resposta obediente na fé e sua fecundidade como mãe de Deus, também assume uma missão universal. Assim, Maria está no coração da Igreja, ou seja, ela se torna o núcleo da Igreja, no qual a ideia da Igreja já se

\footnotetext{
${ }^{15}$ Balthasar cita, respectivamente, PL 39,2105-2106 (dependente de 39, 1985) e PL 183, 73 e Summa Theologiae III, $30,1$.

16 “De tal modo já está superada a ideia de que a Igreja e Maria se relacionam como 'gênero e espécie': ela surge já em Ambrósio Autperto, e um século mais tarde em Pascasio Radpert, que na maternidade de Maria já está acrescida a sua nupcialidade. E como 'Mãe do corpo místico', Maria devia assunir especificamente este atributo eclesial e ser compreendida também como Esposa de Cristo" (Cf. TeoDRAMMATICA, v. 3, p. 286).
} 
encontra plenamente realizada, pois a missão de Maria é universal, assim como a de Cristo, pois ela é a nova Eva. Eles têm em comum a unidade da carne, do espírito, do amor e do sacrifício oferto em comum a Deus. Ela está, pois, no nous da Igreja como esposa perante o seu esposo, como um nous feminino englobante. E a fecundidade de Maria no núcleo da Igreja se manifesta na instituição da Igreja, que possibilita a atualização constante de seu sim para com a história humana (BALTHASAR, 2012, v. 3, p. 278; 282; 324-326).

\section{c) A fecundidade na fundação da instituição eclesial}

A imagem da Igreja como esposa de Cristo, a partir de Maria, que está no coração da Igreja, não se opõe a dimensão institucional da Igreja, mas, pelo contrário, Balthasar entende que a Igreja, na sua dimensão mariana, como escuta e acolhida do Verbo, Igreja-esposa, não pode ser fecunda por si mesma. É a presença da constante Cristo-esposa que a torna fecunda. A Igreja, enquanto esposa, depende totalmente de Cristo para se tornar fecunda, enquanto a Igreja como corpo de Cristo depende totalmente de Cristo em seu ser. A garantia desta atualização permanente de Cristo à sua Igreja-esposa é, precisamente, a instituição eclesial. Ela é necessária enquanto permite a atualização permanente do sim de Maria para com a história humana e também de todo aquele que se apresenta como seguidor de Cristo na Igreja de hoje. É claro que, desse modo, a Igreja não pode atribuir a si mesma o seu ser e o seu viver, pois este deriva sempre de Jesus Cristo, por meio do Espírito Santo (BALTHASAR, 2012, v. 3, p. 318-320; S-Y. JUN, p. 291293).

Neste sentido, a Igreja é, ao mesmo tempo, fecundada e fecunda. Fecundada pela semente da Palavra de Deus, que recebe de Jesus Cristo, pela qual ela concebe e põe no mundo os cristãos, que resulta no nascimento de novos cristãos, ou seja, daqueles que respondem ao apelo da Palavra de Deus e se dispõem, pela fé, à sequela Christi. Fecunda por meio da missão eclesial no mundo. Justamente, para 
Balthasar, a personalidade da Igreja aparece como a pericorese ${ }^{17}$ (circuminseção) das missões pessoais e sociais em cujo centro se encontra a missão mariana (BALTHASAR, 2012, v. 3, p. 326). Por meio do dom do Espírito Santo, cada pessoa ratifica, pelo batismo, o sim de Maria em si mesmo. Todo o sim dado na Igreja ressoa a pessoa e a missão de Maria, que se compenetram tanto nas pessoas quanto nas missões e formam a communio sanctorum (BALTHASAR, 2012, v. 3, p. 322326). A essa dinâmica, entre a fecundação e a fecundidade, Balthasar dá o nome de "círculo eclesial" (BALTHASAR, 2001, p. 165; 2000, p. 19).

Por isso, a dimensão institucional da Igreja se enquadra nas estruturas cristologicamente instituídas por Jesus Cristo, que formam a ordem dos meios indispensáveis para o tempo da peregrinação neste mundo, em função do objetivo de favorecer e alimentar a vida cristã das pessoas que optaram por crer em Cristo, que, por meio do batismo, entraram na Igreja e se tornam membros de Cristo. A instituição eclesial não cria um contraste com o evento nupcial, mas "funda a condição da possibilidade perene de sempre ser atual ao longo da história" (BALTHASAR, 2012, v. 3, p. 326). Assim, Balthasar entende a instituição como a garantia da presença do Cristo-esposo para com a Igreja-esposa, possibilitando permanentemente a vida proveniente de Cristo.

Esta dimensão institucional vem justificada por Balthasar através de cinco aspectos. O primeiro é a encarnação, por meio da qual o Verbo assumiu um corpo humano com a sua constituição própria, e, por esse motivo, a Igreja-esposa deveria ter também uma forma corporal, isto é, a organização. A Igreja recebe esta constituição corporal como recebe a vitalidade que faz acolher o Verbo. Assim, todo o seu ser e o seu viver são recebidos continuamente de Cristo. O segundo aspecto, por consequência do anterior, é a relação entre o nascimento da Igreja como um elemento permanente, que se produz a cada instante, e a estrutura ministerial permanente, a instituição, que é a garantia da possibilidade de participação do

\footnotetext{
${ }^{17} \mathrm{O}$ termo pericorese vem introduzido por Gregório Nazianzeno e adquire seu pleno significado com João Damasceno. Indica a relação que há na Santíssima Trindade: enquanto uma pessoa está em evidência simultânea, as outras estão ao redor. Assim, a obra feita por uma Pessoa é de toda a Santíssima Trindade. Mostra, portanto, a presença e reciprocidade entre as três pessoas divinas.
} 
acontecimento original em cada tempo da história humana, onde vida e forma se antecipam reciprocamente. Desse modo, é possível a permanência da força original da Palavra de Deus na Igreja, assim como foi recebida e compreendida na vida da Tradição, que "a liga a raiz". O terceiro aspecto indica a necessidade de uma regra objetiva por parte da Igreja, que seja garantia do ministério instituído, por dois motivos: o primeiro sublinha que a caridade, em Deus, não existe sem obediência, pois a vida de Cristo se manifesta, em particular, na sua paixão vivida na obediência ao Pai, e que, por isso, também os cristãos devem aprender a obedecer, que deriva na instituição eclesial. O segundo motivo é a pecabilidade dos discípulos de Jesus Cristo, que faz pressupor a existência de uma "regra” de santidade na Igreja que os santifique e seja capaz de educá-los na perfeição do amor obediente. Isto requer que a Igreja esteja radicada na sua origem, ou seja, na existência e na obra do Redentor e na necessidade de uma Igreja de pecadores que busquem sua purificação nele. A santidade da Igreja é constituída pela Igreja santa subjetivamente toda santa, que é a ecclesia mariana immaculata, da qual "naturalmente faz parte também a Igreja celeste perfeita", e também pela Igreja imperfeita formada por pecadores, da qual cada cristão se aproxima (cf. $H b$ 12,22). Aí se introduz o quarto aspecto: Maria mesmo quis tomar a sua cruz para seguir a Jesus. Portanto, todos os cristãos devem submeter-se à "regra do seguimento da cruz”. O papel da autoridade da Igreja é o de manter a regra da cruz. A razão está no acontecimento da encarnação culminar na cruz, que libertou os homens do pecado, e no Espírito, que Cristo, no dia de Pentecostes, fez descer do Pai sobre a Igreja. Por isso, o Espírito Santo é Espírito de liberdade (cf. Gl 5,13), e, como tal, é um apelo a seguir a cruz de Cristo (cf. $R m$ 6,18s) ${ }^{18}$. O quinto aspecto mostra que a cruz pode, em determinados casos, provir de determinadas decisões da autoridade da Igreja, porque Cristo pode se servir da instituição da Igreja para conduzir os seus discípulos no caminho da cruz. Esta situação é fruto da tensão entre o

\footnotetext{
${ }^{18}$ Balthasar afirma que o apelo a seguir Cristo vale não apenas para os membros imperfeitos da Igreja, mas também à lgreja marial, perfeita na totalidade, da forma como Maria foi colocada a mais dura prova por seu Filho, a da cruz a ser tomada e a segui-lo, que é a introdução da Igreja arquétipa sob a regra objetiva do Espírito, isto é, "o cetro de ferro" de Apoc 12,5; 2,27; 19,15; $S / 2,9$. À regra da cruz todos os cristãos são chamados, também aqueles que são formados por Cristo para o ministério, a exemplo de Paulo. A santidade perfeita é, ao mesmo tempo, sabedoria. Por isso, Maria é invocada como "sede da sabedoria". Neste entrelaçamento se encontra o drama interior, entre santidade e sabedoria, constitutivo da Igreja, enquanto ela é considerada Esposa de Cristo e o ministério está enraizado nela (Cf. TeoDRAMMATICA, v. 3, p. 329-330).
} 
ministério episcopal e o ministério profético na Igreja. É verdade que a Tradição e o sendo da fé estão enraizados em toda a Igreja, "marianamente petrina", mas o ministério episcopal deve vigiar a autenticidade do senso profético da fé viva de todo o povo, cuidando e julgando a sua pureza (BALTHASAR, 2012, v. 3, p. 326331; ID., 1961, p. 376).

Na obra Sponsa Verbi, Balthasar aborda este último ponto com o título Charis e carisma, na qual ele mostra a ação do Espírito Santo como o doador de todos os carismas e dons na Igreja, que devem ser vividos de acordo com a caridade (cf. 1Cor 12,6). Desse modo, não há oposição entre instituição e carisma, mas compenetração, pois a instituição é um carisma. Ainda mais por que o Espírito Santo torna a Igreja, e cada membro seu por extensão, templo do Espírito Santo (cf. 1Cor 3,16) (BALTHASAR, 2001, p. 303-315).

Há, ainda, dois temas a serem brevemente referidos aqui, e que já foram acenados anteriormente. O primeiro diz respeito à presença do pecado na Igreja. Na citada obra Sponsa Verbi, Balthasar discorre longamente sobre este tema, intitulado Casta Meretrix, no qual ele mostra à luz de diversos textos do Antigo Testamento, dos Evangelhos e patrísticos a purificação da prostituta pelas núpcias com o enviado de Deus. É o que se verifica, por exemplo, com os profetas, especialmente com Oséias: a relação amorosa de um Deus humilhado pelo adultério da esposa se torna a prefiguração da salvação futura do povo (cf. Os 1-3). O mesmo vale para a Igreja. São as núpcias da Igreja com o Cordeiro que tornam a Igreja santa. É a morte de Cristo na cruz que lava os pecados dos membros da Igreja. Ele, o esposo, é que mantém a Igreja, sua esposa, na castidade, como pura graça. Daí a Igreja é transfigurada e tornada inofensiva, pronta para o apostolado e a realização final, na Parusia (BALTHASAR, 2001, p. 197-290).

O segundo tema é a representação masculina da dimensão institucional da Igreja. É um tema importante para Balthasar, no qual ele retoma a relação entre o masculino e o feminino e a imagem da Igreja como esposa de Cristo. Tal concepção 
traz à luz, novamente, a imagem esponsal entre Deus e as suas criaturas, a nova aliança como objetivo último da encanação do Verbo, o Esposo. Jesus Cristo, como pessoa universal e com uma missão universal, que é a salvação da humanidade pela cruz redentora, está vis-à-vis com Maria, pessoa singular, mas tornada uma pessoa universal pela missão da maternidade divina. Balthasar entende que a instituição foi confiada a homens (vir) que, embora pertencentes à feminilidade englobante da Igreja, embora tirados dela e permanecendo nela mesma, possuem o ministério e a função de personificar a Cristo para a Igreja (BALTHASAR, 2012, v. 3, p. 326-327). Eles agem in personna Christi e, como tal, representam não apenas a missão salvífica universal de Cristo, mas também a sua pessoa como homens, masculinos. Todavia, a ação ministerial dos sacerdotes só é possível em uma Igreja do Filho encarnado, crucificado e ressuscitado que primariamente já foi assumida por uma mulher, aquela que pronunciou o sim capaz de tornar realidade a encarnação do Verbo e que, por isso, contém em si todo o ministério (BALTHASAR, 1999, v. 4, p. 369).

Em consequência destes dois pontos anteriores, resta abordar dois princípios, que são fundamentais para Balthasar: o princípio petrino e o princípio mariano. Ambos são desenvolvidos na obra $O$ complexo antirromano ${ }^{19}$, na qual a articulação entre o masculino e o feminino torna-se fundamental para compreender a relação entre o princípio petrino e o princípio mariano. A missão de Cristo assume a polaridade entre o masculino e o feminino: ela se articula entre o esposo e a esposa e o polo da esposa constitui o "princípio mariano”. Na história, a relação permanente entre o esposo e a esposa esta assegurada graças ao ministério instituído, ou seja, ao princípio petrino. Como sintetiza Antônio Baldini, o masculino representa o princípio petrino e, assim, o ministério ordenado na Igreja se torna um canal de comunicação da graça que vem de Jesus Cristo. O feminino representa o princípio mariano na Igreja, enquanto torna presente a dimensão de

\footnotetext{
${ }^{19}$ O original em alemão já foi citado na nota 11. A tradução francesa é a seguinte: Le complexe antiromano. Paris: Médiaspaul, 1998, 411p. Aí se encontra publicado um artigo de Balthasar redigido por ocasião dos 80 anos do Cardeal Ratzinger, atual Papa Bento XVI (p. 13-24). Ver um comentário sobre os dois princípios em A. BALDINI, Principio petrino e princípio mariano ne "Il complesso antiromano" di Hans Urs von Balthasar, p. 65-99.
} 
acolhimento e conformação ativa à salvação ofertada por Deus (BALDINI, 2003, p. 29).

\section{d) Maria, anima ecclesiastica da Igreja}

Com a afirmação de que Maria é anima ecclesiastica, Balthasar quer dizer que Maria poder ser uma resposta, ao menos inicial, à pergunta quem é a Igreja. Inicial, porque é a sua infinita submissão a Deus, fruto de sua fé, que a converte em sinal ideal, no sentido moral, e real, no sentido físico, da Igreja. Ela se fez na fé, esperança e caridade, tão dócil nas mãos de Deus, que a sua consciência se amplia de pessoa privada individual à eclesial (BALTHASAR, 2001, p. 170).

Como exemplo da passagem da consciência individual para a coletiva, Balthasar cita o apóstolo Paulo: o apóstolo dos gentios fala frequentemente em “eu”. Mas esta maneira de falar ultrapassa a mera referência egocêntrica para culminar na fusão de seu "eu" com o de Cristo, a ponto de ele poder afirmar que "já não sou eu quem vive, é Cristo quem vive em mim” ( $G l 2,20)$, tornando-se um “eu eclesial”. É que o homem velho, o de pecado, morre e dá lugar ao homem novo, o renascido pela graça da regeneração por meio do batismo, e pode, assim, ampliar a sua consciência pessoal ao integrá-la na de Cristo (cf. 2 Cor 5,15; $R m$ 14,8) (BALTHASAR, 2001, p. 171-176). A relação entre Maria e a vocação de Paulo nasce a partir da relação entre o amor e o ministério. Maria se encontra no coração da Igreja por ser uma presença real nela mesma, porque concentra a realidade da resposta eclesial, enquanto Paulo, assim como os Doze (cf. 1Cor 4,9), é uma demonstração representativa da presença e da atuação da missão e do ministério da Igreja, embora Paulo se considere o último entre eles (cf. 2Cor 12,11) (BALTHASAR, 1998, p. 170, 186, 189 e 233). Ele, assim, como Maria, foi dócil nas mãos do Criador e a sua consciência individual passou pela “eclesialização" (BALTHASAR, 2001, p. 170). 
Porém, o que aconteceu com Paulo está acessível a toda pessoa que está disposta a ouvir a pregação da Palavra de Deus e, pela fé, tornar-se membro da Igreja, pois toda a humanidade está representada no sim de Maria. Seguindo Tomás de Aquino, Balthasar reforça seu pensamento ao escrever que o consentimento da Virgem Maria representa toda a humanidade (TOMÁS DE AQUINO, III, 30, 1 c). O sim de Maria, portanto, é "um ato de uma pessoa individual, que se reafirma pela salvação de toda a multidão, antes, de toda a natureza humana” (TOMÁS DE AQUINO, 3 de 3, q. 2 sol 2), da qual vive a fé de todos os cristãos, com maior ou menor intensidade.

Na eucaristia, fonte e ápice da Igreja (Cf. Sacrosanctum Concilium, n. 10), está, também, presente a dimensão feminina através de Maria, porque na encarnação e no nascimento do Verbo, Jesus foi confiado a Maria, antes de ser entregue a toda a Igreja no seu ministério e na comunidade. A união nupcial entre Cristo e a Igreja se realiza na cruz, “onde a Igreja está representada por Maria”, que se torna presente em cada Eucaristia celebrada na Igreja, que é a renovação do sacrifício de Cristo na cruz, quando faz o "em memória de mim”, a pedido de Cristo (cf. 1Cor 11,23-24), como uma ação própria da Igreja. Assim, a eucaristia se prolonga através de todo o tempo da existência terrestre da Igreja em sua dimensão mariana (BALTHASAR, 1999, v. 4, p. 368-372 e 375).

Aqui vale citar a conclusão de Sam-Yong Jun: “A Igreja, portanto, graças à presença de Maria, sua anima immacolata, é a perfeita Esposa de Cristo sem ruga e sem mancha" (JUN, 2012, p. 380).

\section{Conclusão}

Uma possível eclesiologia da Igreja como Esposa de Cristo ${ }^{20}$, seguindo a opinião de A. Baldini, tem vantagens sobre duas eclesiologias em voga no período posterior ao Vaticano II: a eclesiologia de Povo de Deus e a eclesiologia de

\footnotetext{
${ }^{20}$ Não se pode esquecer que Balthasar completa a eclesiologia da Igreja como esposa de Cristo com a da Igreja como Corpo de Cristo e a integra com outras eclesiologias, como a de Povo de Deus e Templo do Espírito Santo.
} 
comunhão (BALDINI, p. 29-30). Muitas vezes, estas duas eclesiologias foram entendidas como alternativas e rivais, tornando-se um verdadeiro dilema eclesiológico recente ${ }^{21}$.

José Comblin questiona a opção do Sínodo de $1985^{22}$ pela eclesiologia de comunhão, porquanto interpreta tal opção como uma "virada" a fim de evitar que a Igreja seja entendida como Povo de Deus, de acordo com a imagem usada pela Lumen Gentium em seu capítulo segundo, e retorne a uma concepção hierárquica da Igreja (COMBLIN, 2002, p. 115-132) ${ }^{23}$, estabelecendo, assim, um debate sobre a imagem a ser utilizada para indicar a eclesiologia conciliar.

Não se trata, de forma alguma, de sustentar rivalidade entre correntes eclesiológicas ou criticar as duas eclesiologias citadas, pois ambas têm fundamento e valor teológico, mas se trata de procurar aprofundar a eclesiologia do ponto de vista teológico. Santiago Madrigal discute este tema e conclui que as duas eclesiologias em questão não podem ser entendidas antagonicamente, mas integradas, pois são complementares (MADRIGAL, 2002, p. 268-270).

Neste sentido, a imagem da Igreja como esposa de Cristo destaca o núcleo da comunhão: o convite à comunhão, que é feito pelo amor do Deus uno e trino a cada pessoa, e que espera uma resposta como entrega absoluta pessoal, ao mesmo tempo, obediente e ativa. Ela mostra Maria como pessoa arquétipa para a Igreja como mulher obediente à vontade de Deus, dócil nas mãos de Deus e fecunda.

Balthasar oferece um fundamento bíblico e cristológico para a noção de comunhão, pois ele a entende não como mera camaradagem ou um grupo de pessoas reunidas por interesses comuns, mas como resultado de um projeto de

\footnotetext{
${ }^{21} \operatorname{Ver}($ MADRIGAL, 2002, p. 245-270; COMBLIN, 2002), onde o autor expõe a abordagem da Igreja através desta imagem bíblica e acusa o Sínodo de 1985 de pretender substituir essa imagem pela eclesiologia de comunhão, para garantir o projeto de minorar a importância do papel dos leigos na Igreja.

22 “A eclesiologia de comunhão é a ideia central e fundamental dos documentos do Concílio. Koinonía - comunhão, fundada na Sagrada Escritura, é tida em grande honra na Igreja antiga e nas Igrejas orientais até nossos dias. Por isso, muito se tem feito desde o Concílio Vaticano II para que a Igreja como comunhão seja entendida de maneira mais clara e traduzida de modo mais concreto na vida" (SÍNODO EXTRAORDINÁRIO DE 1985, Relatio Finalis, ponto II, letra C, n. 1).

${ }^{23}$ "O sinal mais claro da virada foi a substituição do tema povo de Deus pelo de comunhão como centro da eclesiologia. Foi não somente um sinal, mas uma mudança que influenciou toda a mensagem conciliar" (COMBLIN, 2002, p. 118).
} 
Deus, que quis que as missões de seus eleitos se confirmem entre eles e, antes de tudo, com a missão de Maria, em sua união com Cristo. Quanto mais um eleito é fiel à sua missão própria, tanto mais sua pessoa coincide com a sua missão. Como a missão de cada um se interpenetra com as outras missões em Cristo, sua pessoa se abre às outras pessoas teológicas - em primeiro lugar à Maria, na sua união com Cristo - para formar uma comunhão de tipo pericorética. E esta comunhão é a comunhão da Igreja.

A Igreja só pode ser bem compreendida se olhada na perspectiva trinitária, cristológica e mariológica, a partir do mistério de Jesus Cristo e de Maria, o que fará superar uma interpretação meramente hierarquizada ou sociológica da Igreja. O Sínodo de 1985 chamava a atenção para eclesiologias unilaterais presentes no período posterior ao término do Vaticano II: "Não podemos substituir uma falsa visão unilateral da Igreja como puramente hierárquica com uma nova concepção sociológica também ela unilateral. Jesus Cristo está sempre presente na sua Igreja e nela vive como ressuscitado" 24 .

Esta imagem também mostra a raiz da santidade e da fecundidade da Igreja. O cristão está em uma situação feminina na Igreja, enquanto acolhe de forma obediente a Palavra de Deus e a responde pela fé, e, assim, se torna fecundo, enquanto, por meio de seu testemunho vivo de Cristo e sua missão exercida no mundo, o transforma segundo o Reino de Deus (Cf. Lumen Gentium, n. 31). É o consentir para produzir. É a disponibilidade ativa. É o que a Conferência de Aparecida denomina de "discípulo missionário" (CELAM, 2007, n. 28; 101-103; 131-153).

O desenvolvimento de uma antropologia sadia do feminino e a elaboração de uma teologia em base à relação entre o masculino e o feminino é favorecida pela imagem da Igreja como esposa de Cristo, possibilitada pela compreensão antropológica de Balthasar, a partir da relação entre Cristo e a Igreja, de acordo com Ef 5,32. O Papa João Paulo II elabora uma teologia do feminino, na Carta

\footnotetext{
${ }^{24}$ SÍNODO EXTRAORDINARIO DOS BISPOS DE 1985, Relatio finalis II, A, 3.
} 
Apostólica dirigida às mulheres, intitulada Mulieris Dignitatem, publicada no dia 15 de agosto de 1988, lançando mão desta reflexão balthasariana ${ }^{25}$, quando, citando-o na nota 55 , escreve

Mesmo que a Igreja possua uma estrutura "hierárquica", esta, todavia, se ordena integralmente à santidade dos membros corpo místico de Cristo. $\mathrm{E}$ a santidade é medida segundo o "grande mistério", em que a Esposa responde com o dom do amor ao dom do Esposo, e o faz "no Espírito Santo", pois "o amor de Deus foi derramado em nossos corações pelo Espírito Santo que nos foi dado" (cf. $R m$ 5,5). O Concílio Vaticano II, confirmando o ensinamento de toda a tradição, recordou que, na hierarquia da santidade, precisamente a "mulher", Maria de Nazaré, é "figura" da Igreja. Ela "precede" todos no caminho rumo à santidade; na sua pessoa "a Igreja já atingiu a perfeição, pela qual existe sem mácula e sem ruga" (cf. $E f$ 5,27). Neste sentido, pode-se dizer que a Igreja é conjuntamente "mariana" e "apostólico-petrina" (Mulieris Dignitatem, 27).

Enfim, fazendo sua a afirmação de Charles de Foucauld, Balthasar afirma que a Igreja já não é objeto de contemplação, mas ela está concentrada em ato de adoração, por meio da qual se torna permeável o amor único de Cristo (BALTHASAR, 2001, p. 27). Realmente, colocar-se de joelhos dá condições de se penetrar no mistério de Deus único, no qual está presente a Igreja, a amada de Jesus Cristo, que, por ser sacramento de salvação (cf. Lumen Gentium, n. 1), torna presente no mundo de hoje o Verbo encarnado, o Filho de Deus, que veio ao mundo por meio de Maria.

\footnotetext{
${ }^{25}$ Na alocução à Cúria Romana, por ocasião dos votos natalinos, o Papa João Paulo II, em 22 de dezembro de 1987, já havia citado Balthasar: "La dimensione mariana della Chiesa emerge dalla similitudine dei compiti nei confronti del Cristo totale: ad essa infatti si applica in modo particolare la parola di Gesù secondo cui 'chi compie la volontà di Dio è mio fratello, sorella e madre' (cf. Mc 3, 35); anche la Chiesa, come Maria, vive nella grazia, nella sottomissione allo Spirito Santo, alla sua luce interpreta i segni e le necessità dei tempi, e avanza nel cammino della fede in piena docilità alla voce dello Spirito. In questo senso, la dimensione mariana della Chiesa antecede quella petrina, pur essendole strettamente unita e complementare. Maria, l'Immacolata, precede ogni altro, e, ovviamente, lo stesso Pietro e gli apostoli: non solo perché Pietro e gli apostoli, provenendo dalla massa del genere umano che nasce sotto il peccato, fanno parte della Chiesa sancta ex peccatoribus, ma anche perché il loro triplice munus non mira ad altro che a formare la Chiesa in quell'ideale di santità, che già è preformato e prefigurato in Maria. Come bene ha detto un teologo contemporaneo, 'Maria è "regina degli apostoli', senza pretendere per sé i poteri apostolici. Essa ha altro e di più" (BALTHASAR, 1980, p. 181). Singolarmente significativa si rivela, da questo punto di vista, la presenza di Maria nel cenacolo, ove Ella assiste Pietro e gli altri apostoli, pregando con loro e per loro in attesa dello Spirito".
}

Horizonte, Belo Horizonte, vol. 13, no. 37, p. 446-477, Jan./Mar. 2015 - ISSN 2175-5841 


\section{REFERÊNCIAS}

AQUINO, Tomás de. Setentiae III, dist. 3, 2, sol 2. São Paulo: Loyola, 2003-2007.

AQUINO, Tomás de. Summa Theologiae 3 ad 3, q. 2 sol 2. São Paulo: Loyola, 20032007.

BALDINI, Antonio. Principio petrino e principio mariano ne "Il complesso antiromano" di Hans Urs von Balthasar. Lugano: Europress, 2003, p. 41-48.

BALTHASAR, Hans Urs von. Dank des Preisträgers an der Verleihung dês Wolfgang Amadeus Mozart. In : GUERRIERO, E. Hans Urs von Balthasar. Eine Monographie, übertragen von Carl Franz Müller, durschgesehen von Florian Pitschl und Cornelia Capol. Freiburg: Johannes Verlag Einsiedeln, 1983, p. 419-424.

BALTHASAR, Hans Urs von. Le complexe antiromain. (Nouvelle édition). Paris: Médiaspaul, 1998, p. 8.

BALTHASAR, Hans Urs von. Qui est l’Église? Saint-Maur: Parole et Silence, 2000.

BALTHASAR, Hans Urs von. Sponsa Verbi. Ensayos Teológicos II. Madrid: Encuentro e Cristandad, 2001.

BALTHASAR, Hans Urs von. Teodrammatica, vol. 2. Milano: Jaca Book, 2012.

BALTHASAR, Hans Urs von. Teodrammatica, vol. 3. Milano: Jaca Book, 2012.

BALTHASAR, Hans Urs von. Teodrammatica, vol. 4. Milano: Jaca Book, 1999.

BÍBLIA DE JERUSALÉM. São Paulo: Paulinas, 1985.

COMblin, José. Povo de Deus. São Paulo: Paulus, 2002.

CONCÍLIO ECUMÊNICO VATICANO II. Compêndio do vaticano II. Constituições, Decretos e Declarações. Petrópolis : Vozes, 2000.

CONGAR, Yves. Marie-Joseph. La personne "Église”. In : Revue Thomiste LXXI, n. 4 (1971), p. 613-640.

CONSELHO EPISCOPAL LATINO-AMERICANO (CELAM). Documento de Aparecida. Texto conclusivo da V Conferência Geral do Episcopado Latino-Americano. São Paulo:

Paulus; Paulinas, 2007.

DANIÉLOU, Jean. Et qui est mon prochain? Memoires. Paris: Stock, 1974.

GUERRIERO, Elio. Hans Urs von Balthasar. Eine Monographie, übertragen von Carl Franz Müller, durschgesehen von Florian Pitschl und Cornelia Capol. Freiburg: Johannes Verlag Einsiedeln, 1983, p. 419-424. 
GUERRIERO, Elio. Hans Urs von Balthasar. São Paulo: Loyola, 2010.

JUN, Sam-Yong. Maria-Chiesa Sponsa Verbi e Il pensiero de H.U. Von

Balthasar. Assisi: Cittadella, 2012.

MADRIGAL, Santiago. Los nombres de la Iglesia en el tempo posconciliar: pueblo di Dios y mistero di comunión. In S. MADRIGAL, Vaticano II: remembranza y actualización. Esquemas para una Eclesiologia. Santander: Sal Terrae, 2002, p. 245-270.

MODA, Aldo. Hans Urs von Balthasar. In VANZAN, Piersandro E schultz, Hans Jürgen, Lessico dei teologi del secolo XX (Mysterium Salutis/Supplemento, v. 12). Brescia : Queriniana, 1978, p. 564-577.

PAPA JOÃO PAULO II. Carta Apostólica Mulieris Dignitatem. São Paulo: Paulinas, 1988.

SAINT-PIERRE, Mario. Hans Urs von Balthasar. In : J. GENEST (Org.). Penseurs et apôtres du XXe. Siècle. Montréal: Fides, 2001, p. 43-54.

SCOLA, Angelo. Hans Urs von Balthasar: um estilo teológico. Madrid: Encuentro, 1997.

SÍNODO EXTRAORDINÁRIO DE 1985, Relatio Finalis Ecclesia sub verbo Dei mysteria Christi celebrans pro salute mundi. In TESTACCI, Brubo e MOCELLIN, Guido (a cura de), Enchiridion Vaticanum. Documenti ufficiali della Santa Sede 1983-1985, v. 9.

Bologna: Dehoniane, 1987, n. 1779-1818. 